\title{
Prognostic significance of angiogenesis in gastrointestinal stromal tumor
}

\author{
Masakazu Imamura ${ }^{1}$, Hidetaka Yamamoto ${ }^{1}$, Norimoto Nakamura ${ }^{1}$, Yoshinao Oda ${ }^{1}$, \\ Takashi Yao ${ }^{1}$, Yoshihiro Kakeji ${ }^{2}$, Hideo Baba ${ }^{3}$, Yoshihiko Maehara ${ }^{2}$ and \\ Masazumi Tsuneyoshi ${ }^{1}$
}

${ }^{1}$ Department of Anatomic Pathology, Graduate School of Medical Sciences, Kyushu University, Higashiku, Fukuoka, Japan; ${ }^{2}$ Department of Surgery and Science, Graduate School of Medical Sciences, Kyushu University, Higashiku, Fukuoka, Japan and ${ }^{3}$ Department of Gastroenterological Surgery, Graduate School of Medical Sciences, Kumamoto University, Kumamoto, Japan

\begin{abstract}
Angiogenesis is important in the growth and metastasis of various kinds of solid tumors. To investigate the potential role of angiogenesis in gastrointestinal stromal tumor (GIST), an immunohistochemical analysis was performed in 95 cases of GISTs for microvessel density (MVD) and vascular endothelial growth factor (VEGF) expression. MVD was evaluated with immunohistochemical staining for CD31. A high level of MVD was significantly correlated with overexpression of VEGF, tumor location (intestine $>$ stomach), tumor size ( $\geq 5 \mathrm{~cm}$ ), tumor grade (high $>$ intermediate $>$ low grade) $(P=<0.0001,0.0422,0.0006,0.0359$, respectively). Of the 70 GISTs analyzed, $K I T$ exon 11 mutations were detected in 45 cases (64.3\%) and $K I T$ exon 9 mutations in two cases (2.9\%). No mutations were found in KIT exons 13 and 17, and platelet-derived growth factor receptor-alpha exons 12 and 18. Interestingly, VEGF expression level was significantly higher in the non-KIT exon 11 mutant group than in the $K I T$ exon 11 mutant group $(P=0.0266)$. In univariate analysis, tumor grade (high grade), tumor size ( $\geq 5 \mathrm{~cm}$ ), mitotic count ( $\geq 5 / 50$ high-power fields), Ki-67 labeling index ( $\geq 4.6 \%$ ), MVD ( $\geq 7.0 / 0.95 \mathrm{~mm}^{2}$ ) and VEGF expression (high) were significantly associated with a shorter period of disease-free survival $(P=<0.0001,0.0199,0.00550 .0027,0.0028$ and 0.0302 , respectively). In multivariate analysis, tumor grade and MVD were identified as independent worse prognostic factors $(P=0.0007,0.0152$, respectively). In conclusion, our results suggest that the evaluation of MVD and VEGF expression is useful for predicting the aggressive biologic behavior of GIST, and that angiogenesis associated with VEGF may play an important role, at least in part, in the progression of GIST.
\end{abstract}

Modern Pathology (2007) 20, 529-537. doi:10.1038/modpathol.3800767; published online 2 March 2007

Keywords: gastrointestinal stromal tumor; vascular endothelial growth factor; angiogenesis; KIT

Gastrointestinal stromal tumors (GISTs) are the most common mesenchymal tumor of the gastrointestinal tract. $^{1}$ The stomach is the most frequent site of origin, followed by the small intestine. GISTs express the receptor tyrosine kinase KIT. In recent years it has been established that $75-90 \%$ of GISTs harbor a gain of function mutation of the KIT gene at exons $9,11,13$ and $17 .^{2-5}$ Moreover, recent studies have described activating mutations of plateletderived growth factor receptor-alpha (PDGFRA) at exons 12 and 18 in a minor subset (approximately $5-7 \%$ ) of GIST. ${ }^{6}$ Although GISTs exhibit a spectrum

Correspondence: Dr H Yamamoto, MD, Department of Anatomic Pathology, Pathological Sciences, Graduate School of Medical Sciences, Kyushu University, 3-1-1 Maidashi, Higashi-ku, Fukuoka 812-8582, Japan.

E-mail: hidetaka@surgpath.med.kyushu-u.ac.jp

Received 22 September 2006; revised 16 January 2007; accepted 18 January 2007; published online 2 March 2007 of biologic behavior from benign to malignant, the molecular mechanism of tumor progression has not been fully clarified. Previous studies have reported the prognostic significance of tumor size, mitotic counts, tumor grade, Ki-67 labeling index (LI), ${ }^{7}$ KIT mutation type, ${ }^{4,8,9}$ p16 inactivation ${ }^{10}$ and overexpression of cell-cycle regulators such as cyclin A, cyclin B1 and cdc2. ${ }^{11}$

Angiogenesis is one of the key steps in the growth and metastasis of solid tumors. ${ }^{12,13}$ Angiogenesis is induced by the paracrine release of angiogenic molecules from tumor cells and stromal cells. Vascular endothelial growth factor (VEGF) plays a major role in promoting tumor angiogenesis. ${ }^{14,15}$ Interestingly, a recent cDNA microarray study showed that the VEGF mRNA level in KIT-wild GIST was higher than that in KIT mutant (exon 11 or 9) GIST. ${ }^{16}$ However, there has been no study of the association among KIT mutation type, angiogenesis and VEGF expression in GISTs. 
Imatinib mesylate (Gleevec/Glivec) is the tyrosine kinase inhibitor targeting KIT and PDGFRA in GIST. Recent data have shown a correlation between the effect of imatinib and the type of KIT mutation; tumors with KIT exon 11 mutation are more likely to respond to imatinib than those with other types of mutation or wild-type $K I T T^{17,18}$ Sunitinib malate (SU11248) is a novel multitargeted tyrosine kinase inhibitor with antitumor and antiangiogenic activities, which performs by blocking KIT and PDGFRA as well as VEGFR. ${ }^{19}$ Interestingly, recent clinical studies have reported that SU11248 was effective in a subset of imatinib-resistant GISTs. ${ }^{20-22}$

In this study, we evaluated the prognostic values of angiogenesis, VEGF expression and KIT mutations in a large series of GISTs to provide a rationale for novel 'tailored' molecular-targeted therapy.

\section{Materials and methods}

\section{Case Materials and Pathological Evaluation}

We obtained 95 cases of primary GISTs from the file of the Department of Anatomic Pathology of Kyushu University between 1986 and 2004. All the cases used in this study were localized in the stomach or intestine, and were surgically resected with negative margins. Cases with distant metastasis and peritoneal dissemination at the initial operation were excluded from this study. The diagnosis of all cases of GIST was made based on histological features and immunohistochemical expression of KIT. Each GIST was evaluated for clinicopathological and histological features, including tumor size, location, cell type (spindle, epithelioid or mixed type), mitotic count and tumor grade. Tumors were classified into very low-, low-, intermediate- and high-grade groups depending on tumor size $(2,5$ or $10 \mathrm{~cm})$ and mitotic count ( 5 or 10 per 50 high-power fields (HPFs)), in accordance with the consensus meeting report at the National Institutes of Health. ${ }^{23}$ The tumor grading was assigned by two pathologists (NN and HY).

\section{Immunohistochemical Staining and Evaluation}

Histological sections $(4 \mu \mathrm{m})$ of $10 \%$ formalin-fixed, paraffin-embedded samples were used for the immunohistochemical examination. The primary antibodies were as follows: c-kit (polyclonal, A4502, dilution; 1/100, Dako, Carpinteria, CA, USA), CD34 (QB-end-10, dilution; 1/50, Novocastra, Newcastle, UK), Ki-67 (MIB-1, dilution; 1/100, DAKO), CD31 (M0823, dilution; 1/20, DAKO) and VEGF (14-124, dilution; 1/100, Oncogene Research Products, Cambridge, MA, USA). The sections were incubated with primary antibodies at $4^{\circ} \mathrm{C}$ overnight, followed by the streptoavidin-biotin-peroxidase method (Histofine SAB-PO Kit, Nichirei, Tokyo, Japan). The sections were then reacted in a $3,3^{\prime}$-diamino- benzidine peroxytrichloride substrate solution, and were counterstained with hematoxylin.

Microvessel density (MVD) was quantified using immunohistochemical staining for CD31 as a marker for neovessel endothelium according to the previous report by Horak et $a l^{24}$ with a slight modification. The most vascularized area ('hot spot') was identified by scanning the sections at lower power view $(\times 40)$. Then, the number of CD31-positive microvessels was counted in 10 selected hot spots at a magnification of $\times 200\left(0.95 \mathrm{~mm}^{2}\right.$ field area, Olympus BX40 microscope). The mean count of 10 hot spots was defined as the MVD per $0.95 \mathrm{~mm}^{2}$ field area, in order to avoid the bias concerning the selection of hot spot.

As for the evaluation of VEGF expression, the cytoplasmic staining intensity in the GIST cells was graded as 0 (no staining), 1 (weak staining) or 2 (strong staining). When the tumor cells were stained for VEGF, the staining pattern was essentially diffuse and of homogenous intensity throughout the section in our preliminary study. Therefore, we evaluated the expression of VEGF by staining intensity.

MVD and VEGF scoring were performed by two pathologists (HY and MI), who were not aware of the clinical characteristics of the patients.

\section{Analysis of KIT and PDGFRA Mutations}

Mutations in exons 9, 11, 13 and 17 of the KIT gene and in exons 12 and 18 of the PDGFRA gene were examined in 70 cases of GIST according to the previously described polymerase chain reaction (PCR) and direct sequencing methods. ${ }^{25}$ In brief, genomic DNA was extracted from paraffinembedded tissue by using standard proteinase $\mathrm{K}$ digestion and phenol/chloroform extraction. The DNA sequences for each exon were amplified for the first PCR with each primer for 40 cycles $\left(94^{\circ} \mathrm{C}\right.$ for $1 \mathrm{~min}, 52-56^{\circ} \mathrm{C}$ for $1 \mathrm{~min}$ and $72^{\circ} \mathrm{C}$ for $1 \mathrm{~min}$ ) by using a thermal cycler ( $\mathrm{T}$ Gradient, Biometra, Goettingen, Germany). The PCR products were electrophoresed through $2.0 \%$ agarose gel with ethidium bromide to confirm the correct amplification. The amplified products were then purified by centrifugal filter devices of Microcon (Millipore, Bedford, MA, USA). After the purification, direct sequencing was carried out by the dideoxy chain termination method using a Perkin-Elmer ABI Prism 310 sequence analyzer (Applied Biosystems, Foster City, CA, USA).

\section{Follow-up and Statistical Analysis}

The correlation among the clinicopathological parameters, VEGF expression and the results of KIT gene and PDGFRA gene mutational analysis was analyzed by the $\chi^{2}$ test, whereas that between MVD counts and clinicopathological factors was analyzed by the Mann-Whitney $U$-test. The correlation 
among tumor size, mitotic count, MVD and tumor grade was analyzed using Spearman's correlation analysis. We analyzed disease-free survival (DFS), for which the end points included any relapse (local recurrence and/or metastasis) of the GISTs. Univariate analysis of DFS was performed by the Kaplan-Meier method with a log-rank test. For multivariate analysis of DFS, we used the Cox proportional hazards model. A $P$-value of less than 0.05 was considered statistically significant.

\section{Results}

\section{Clinicopathological Findings}

The clinicopathological findings in GIST are summarized in Table 1 . The 95 patients comprised 48 men and 47 women, ranging in age from 23 to 93 years (median, 64 years). The tumors were located in the stomach (64 cases) and small intestine (31 cases). The tumors ranged from 0.8 to $27 \mathrm{~cm}$ in size (median, $5.5 \mathrm{~cm}$ ). Histologically, 92 tumors were of the spindle-cell type, one tumor was of the epithelioid-cell type and the remaining two were of the mixed spindle- and epithelioid-cell type (Figure 1a, b). Mitotic counts varied from 0 to 112 per $50 \mathrm{HPF}$ (median, 3/50 HPF) and Ki-67 LI varied from 1.0 to $16.4 \%$ (median, $4.6 \%$ ). According to the riskgrading system, seven cases were classified as very low grade, 22 as low grade, 38 as intermediate grade and 28 as high grade.

\section{MVD and VEGF Expression}

MVD ranged from 0.3 to $49.0 / 0.95 \mathrm{~mm}^{2}$ (median, $7.0 / 0.95 \mathrm{~mm}^{2}$ ) (Figure 1c, d). VEGF expression was seen in the cytoplasm of tumor cells. VEGF expression showed no staining (score of 0) in six cases $(6.3 \%)$, weak staining (score of 1) in 44 cases

Table 1 Clinicopathological data and risk grade in 95 cases of GISTs

\begin{tabular}{|c|c|c|c|c|}
\hline \multirow[t]{2}{*}{ Factors } & \multicolumn{3}{|c|}{ Tumor-grade } & \multirow[t]{2}{*}{ P-value } \\
\hline & $\begin{array}{c}\text { Very } \\
\text { low+low } \\
(\mathrm{n}=29)\end{array}$ & $\begin{array}{l}\text { Intermediate } \\
\qquad(\mathrm{n}=38)\end{array}$ & $\begin{array}{c}\text { High } \\
(\mathrm{n}=28)\end{array}$ & \\
\hline Gender & & & & 0.9881 \\
\hline Male $(n=48)$ & 15 & 19 & 14 & \\
\hline Female $(n=47)$ & 14 & 19 & 14 & \\
\hline Age (year) ${ }^{\mathrm{a}}$ & $66(52-72)$ & $65(51-76)$ & $60(46-71)$ & 0.8442 \\
\hline Site & & & & 0.9167 \\
\hline Stomach $(n=64)$ & 20 & 26 & 18 & \\
\hline Intestine $(n=31)$ & 9 & 12 & 10 & \\
\hline Histological type & & & & 0.5192 \\
\hline Spindle $(n=92)$ & 27 & 37 & 28 & \\
\hline $\begin{array}{l}\text { Epithelioid } \\
(n=1)\end{array}$ & 1 & 0 & 0 & \\
\hline Mixed $(n=2)$ & 1 & 1 & 0 & \\
\hline
\end{tabular}

${ }^{\mathrm{a}}$ Values were expressed as median levels (interquartile range).
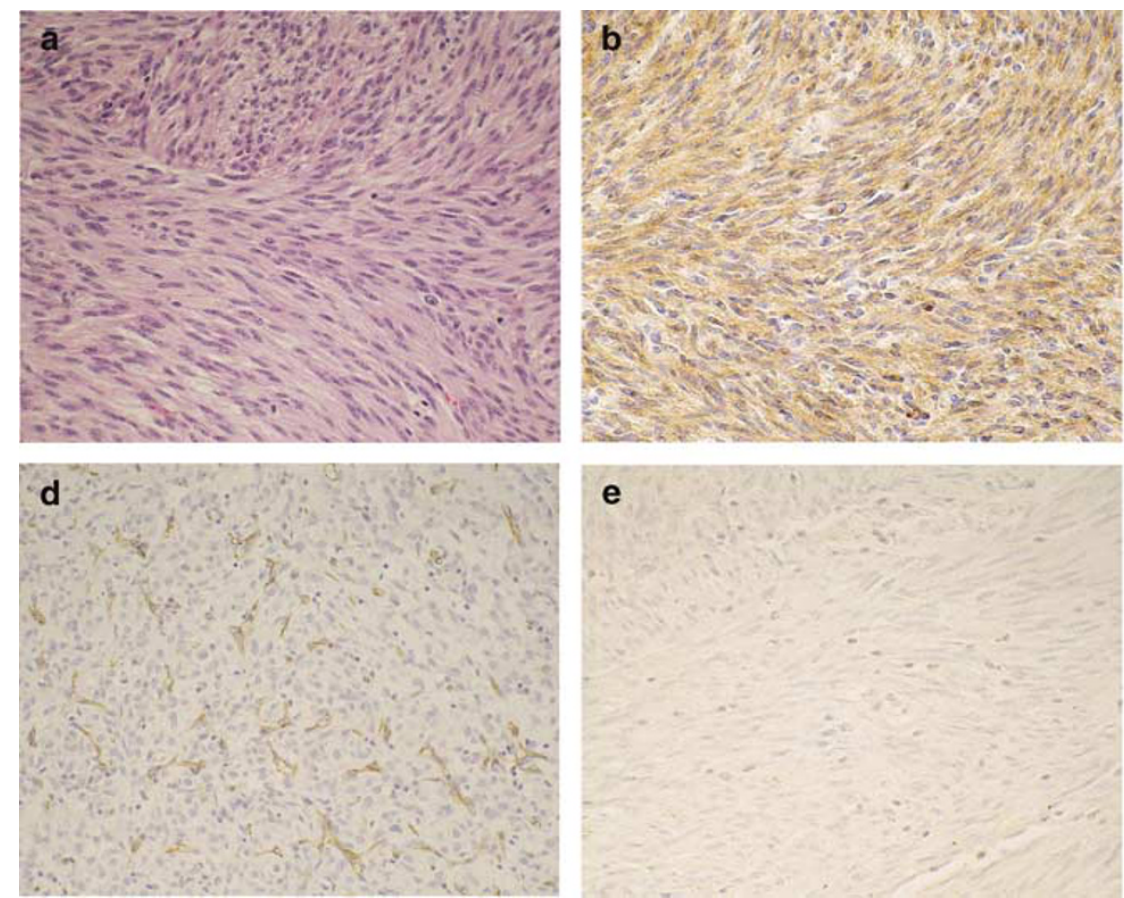

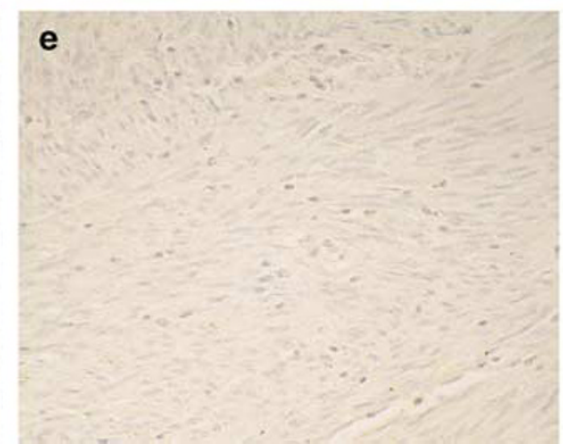

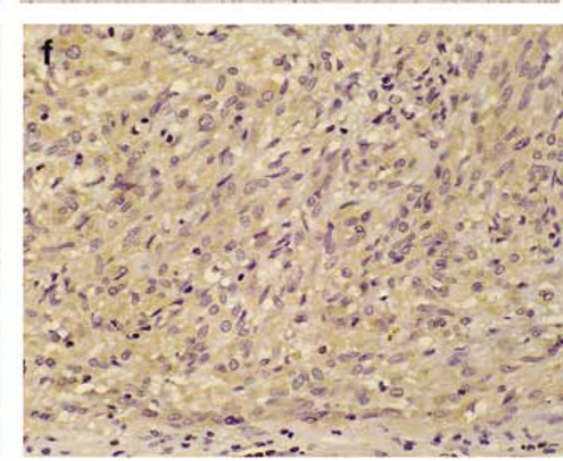

Figure 1 Histological and immunohistochemical findings in GIST (a, b). (a) GIST, spindle-cell type. Spindle cells proliferate in fascicles. (b) Immunohistochemical stain for c-kit. Tumor cells are diffusely positive. Immunohistochemical staining with CD31 for quantification of MVD in GIST (c, d). (c) GIST showing low MVD $\left(2.8 / 0.95 \mathrm{~mm}^{2}\right)$. (d) GIST showing high MVD (40.4/0.95 mm²). Immunohistochemical staining for VEGF expression in GIST (e, f). (e) Very weak expression of VEGF in tumor cells. (f) Strong expression of VEGF in tumor cells. 
Table 2 Correlation between MVD and clinicopathological factors

\begin{tabular}{|c|c|c|}
\hline Factors & $M V D\left(/ 0.95 \mathrm{~mm}^{2}\right)^{\mathrm{a}}$ & $\mathrm{P}$-value \\
\hline Age (year) & & 0.7265 \\
\hline$<64(n=47)$ & $8.3(2.4-11.1)$ & \\
\hline$\geq 64(n=48)$ & $5.8(2.4-13.1)$ & \\
\hline Gender & & 0.0399 \\
\hline Male $(n=48)$ & $9.4(4.3-13.5)$ & \\
\hline Female $(n=47)$ & $4.6(2.0-10.4)$ & \\
\hline Site & & 0.0422 \\
\hline Stomach $(n=64)$ & $6.7(1.8-10.8)$ & \\
\hline Intestine $(n=31)$ & $9.0(4.6-19.9)$ & \\
\hline Size & & 0.0006 \\
\hline$<5 \mathrm{~cm}(n=39)$ & $4.1(1.6-9.0)$ & \\
\hline$\geq 5 \mathrm{~cm}(n=56)$ & $9.4(4.1-15.3)$ & \\
\hline Cell type & & 0.5656 \\
\hline Spindle $(n=92)$ & $6.9(2.4-11.6)$ & \\
\hline Epithelioid and mixed $(n=3)$ & $11.2(4.1-23.5)$ & \\
\hline Mitosis & & 0.6785 \\
\hline$<5 / 50 \mathrm{HPF}(n=55)$ & $6.3(2.4-11.7)$ & \\
\hline$\geq 5 / 50 \mathrm{HPF}(n=40)$ & $8.2(2.4-11.3)$ & \\
\hline Tumor grade & & 0.0359 \\
\hline Very low+low $(n=29)$ & $4.6(1.7-9.4)$ & \\
\hline Intermediate $(n=38)$ & $8.3(2.4-11.8)$ & \\
\hline High $(n=28)$ & $8.7(3.4-14.6)$ & \\
\hline Ki-67 index & & 0.2579 \\
\hline$<4.6 \%(n=47)$ & $5.1(1.7-11.4)$ & \\
\hline$\geq 4.6 \%(n=48)$ & $8.5(3.6-11.8)$ & \\
\hline VEGF expression & & $<0.0001$ \\
\hline Low $(n=50)$ & $3.6(1.6-9.1)$ & \\
\hline High $(n=45)$ & $10.4(4.9-17.3)$ & \\
\hline
\end{tabular}

MVD, microvessel density; HPF, high-power field; VEGF, vascular endothelial growth factor.

${ }^{\mathrm{a}}$ Values were expressed as median levels (interquartile range).

$(46.3 \%)$ and strong staining (score of 2 ) in 45 cases $(47.4 \%)$ (Figure 1e, f). The immunohistochemical expression levels of VEGF were classified as low expression (scores of 0 and 1 ) and high expression (score of 2) in 50 cases $(52.6 \%$ ) and 45 cases (47.4\%), respectively. The correlation among MVD, VEGF expression and clinicopathological data is shown in Tables 2 and 3. MVD was significantly correlated with gender, primary site (stomach vs intestine), tumor size $(<5 \mathrm{~cm} v S \geq 5 \mathrm{~cm})$, tumor grade, VEGF expression (low vs high) $(P=0.0399$, $0.0422,0.0006,0.0359,<0.0001$, respectively, Table 2). VEGF expression was significantly correlated with gender and primary site $(P=0.0101,0.0198$, respectively, Table 3).

\section{KIT and PDGFRA Mutations}

Of the 70 GISTs analyzed, KIT exon 11 mutations were detected in 45 cases $(64.3 \%)$. and KIT exon 9
Table 3 Correlation between VEGF expression and clinicopathological factors

\begin{tabular}{|c|c|c|c|}
\hline \multirow[t]{2}{*}{ Factors } & \multicolumn{2}{|c|}{ VEGF expression } & \multirow[t]{2}{*}{ P-value } \\
\hline & $\begin{array}{c}\text { Low } \\
(\mathrm{n}=50)\end{array}$ & $\begin{array}{c}\text { High } \\
(\mathrm{n}=45)\end{array}$ & \\
\hline Age (year) & & & 0.1799 \\
\hline$<64(n=47)$ & 28 & 19 & \\
\hline$\geq 64(n=48)$ & 22 & 26 & \\
\hline Gender & & & 0.0101 \\
\hline Male $(n=48)$ & 19 & 29 & \\
\hline Female $(n=47)$ & 31 & 16 & \\
\hline Site & & & 0.0198 \\
\hline Stomach $(n=64)$ & 39 & 25 & \\
\hline Intestine $(n=31)$ & 11 & 20 & \\
\hline Size & & & 0.3015 \\
\hline$<5 \mathrm{~cm}(n=39)$ & 23 & 16 & \\
\hline$\leq 5 \mathrm{~cm}(n=56)$ & 27 & 29 & \\
\hline Cell type & & & 0.4963 \\
\hline Spindle $(n=92)$ & 49 & 43 & \\
\hline Epithelioid and mixed $(n=3)$ & 1 & 2 & \\
\hline Mitosis & & & 0.2200 \\
\hline$<5 / 50 \mathrm{HPF}(n=55)$ & 26 & 29 & \\
\hline$\geq 5 / 50 \mathrm{HPF}(n=40)$ & 24 & 16 & \\
\hline Tumor grade & & & 0.4197 \\
\hline Very low+low $(n=29)$ & 13 & 16 & \\
\hline Intermediate $(n=38)$ & 23 & 15 & \\
\hline High $(n=28)$ & 14 & 14 & \\
\hline Ki-67 index & & & 0.3523 \\
\hline$<4.6 \%(n=47)$ & 27 & 20 & \\
\hline$\geq 4.6 \%(n=48)$ & 23 & 25 & \\
\hline
\end{tabular}

VEGF, vascular endothelial growth factor.

Table 4 Results of KIT and PDGFRA mutation analysis

\begin{tabular}{lc}
\hline Gene & Positive cases $(\%)$ \\
\hline KIT & \\
Exon 11 & $45 / 70(64.3)$ \\
$\quad$ Deletion & 26 \\
Substitution & 14 \\
Deletion+substitution & 5 \\
Exon 9 & $2 / 70(2.9)$ \\
Exon 13 & $0 / 70(0)$ \\
Exon 17 & $0 / 70(0)$ \\
PDGFRA & $0 / 70(0)$ \\
KIT, PDGFRA wild & $23 / 70(32.8)$
\end{tabular}

PDGFRA, platelet-derived growth factor alpha.

mutations in two cases $(2.9 \%)$ (Table 4$)$. No mutations were found in KIT exons 13 and 17 and PDGFRA exons 12 and 18. Among the 45 tumors with exon 11 mutations, the amino-acid alteration patterns were deletions in 26 tumors $(57.8 \%)$, substitutions in 14 (31.1\%), deletions with substitutions in five tumors $(11.1 \%)$. Most of the exon 11 mutations were located between codons 550 and 570. Both exon 9 mutations were insertions of six 
Table 5 Correlation between the KIT exon 11 mutation and clinicopathological factors

\begin{tabular}{|c|c|c|c|}
\hline \multirow[t]{2}{*}{ Factors } & \multicolumn{2}{|c|}{ KIT exon 11 muation } & \multirow[t]{2}{*}{ P-value } \\
\hline & $+(n=45)$ & $-(n=25)$ & \\
\hline Age (year) & & & 0.8301 \\
\hline$<64(n=38)$ & 24 & 14 & \\
\hline$\geq 64(n=32)$ & 21 & 11 & \\
\hline Gender & & & 0.5684 \\
\hline Male $(n=36)$ & 22 & 14 & \\
\hline Female $(n=34)$ & 23 & 11 & \\
\hline Site & & & 0.1736 \\
\hline Stomach $(n=49)$ & 34 & 15 & \\
\hline Intestine $(n=21)$ & 11 & 10 & \\
\hline Size & & & 0.3429 \\
\hline$<5 \mathrm{~cm}(n=23)$ & 13 & 10 & \\
\hline$\geq 5 \mathrm{~cm}(n=47)$ & 32 & 15 & \\
\hline Cell type & & & 0.2528 \\
\hline Spindle $(n=67)$ & 44 & 23 & \\
\hline $\begin{array}{l}\text { Epithelioid and mixed } \\
(n=3)\end{array}$ & 1 & 2 & \\
\hline Mitosis & & & 0.4055 \\
\hline$<5 / 50 \mathrm{HPF}(n=41)$ & 28 & 13 & \\
\hline$\geq 5 / 50 \mathrm{HPF}(n=29)$ & 17 & 12 & \\
\hline Tumor grade & & & 0.6935 \\
\hline Very low+low $(n=17)$ & 10 & 7 & \\
\hline Intermediate $(n=32)$ & 20 & 12 & \\
\hline High $(n=21)$ & 15 & 6 & \\
\hline Ki-67 LI & & & 0.1539 \\
\hline$<4.6 \%(n=34)$ & 19 & 15 & \\
\hline$\geq 4.6 \%(n=36)$ & 26 & 10 & \\
\hline VEGF expression & & & 0.0266 \\
\hline Low $(n=32)$ & 25 & 7 & \\
\hline High $(n=38)$ & 20 & 18 & \\
\hline $\operatorname{MVD}\left(/ 0.95 \mathrm{~mm}^{2}\right)^{\mathrm{a}}$ & $\begin{array}{c}8.0 \\
(3.1-11.9)\end{array}$ & $\begin{array}{c}10.4 \\
(3.8-15.0)\end{array}$ & 0.4185 \\
\hline
\end{tabular}

MVD, microvessel density; HPF, high-power field; VEGF, vascular endothelial growth factor.

${ }^{\mathrm{a}}$ Values were expressed as median levels (interquartile range).

nucleotides, resulting in duplications of amino-acid residues $\mathrm{Ala}^{502}-\mathrm{Tyr}^{503}$. We then compared the clinicopathological and immunohistochemical findings between the KIT exon 11 mutant group and the non-KIT exon 11 mutant group, including the KIT wild-type gene (Table 5). The non-KIT exon 11 mutant group showed significantly higher expression of VEGF as compared with the KIT exon 11 mutant group $(P=0.0266)$. MVD was not correlated with the KIT genotype.

\section{Statistical Analysis for Prognosis}

Follow-up information was available for 80 patients. The follow-up period ranged from 3.6 to 160.7 months (mean 48.4 months, median 34.8 months). All 80 patients were free of distant metastasis and
Table 6 Univariate and multivariate analysis of various parameters for disease-free survival (DFS) in 80 patients after curative surgery

Variables P-value

\begin{tabular}{lrc} 
& & \\
\cline { 2 - 3 } & Univariate & Multivariate \\
\hline $\begin{array}{l}\text { Tumor grade } \\
\text { (very low-intermediate vs high) }\end{array}$ & $<0.0001$ & 0.0007 \\
Tumor size $(<5$ vs $\geq 5 \mathrm{~cm})$ & 0.0199 & 0.7483 \\
Mitotic count $(<5 / 50$ vs $\geq 5 / 50 \mathrm{HPF})$ & 0.0055 & 0.8940 \\
Ki-67 LI $(<4.6$ vs $\geq 4.6)$ & 0.0027 & 0.2275 \\
MVD grade $(<7.0$ vs $\geq 7.0)$ & 0.0028 & 0.0152 \\
VEGF expression (low vs high) & 0.0302 & 0.3794 \\
Site (stomach vs intestine) & 0.1954 & 0.8953
\end{tabular}

MVD, microvessel density; HPF, high-power field; VEGF, vascular endothelial growth factor.

peritoneal dissemination at the initial operation. Relapse of the tumor was seen in 12 patients $(15.0 \%)$ of 80 patients, including one of low-grade GISTs (liver metastasis), one of intermediate-grade GISTs (liver metastasis) and 10 of high-grade GISTs (seven cases of liver metastasis, one case of lung metastasis, one case of local recurrence and one case of both liver metastasis and peritoneal dissemination). The presence of peritoneal disease and distant metastasis was significantly associated with tumor grade $(P<0.0001)$.

The prognostic values of several factors for DFS were analyzed in 80 cases (Table 6 and Figure 2). In univariate analysis, tumor grade (high grade), tumor size $(\geq 5 \mathrm{~cm})$, mitotic count ( $\geq 5 / 50 \mathrm{HPF})$, Ki-67 LI $(\geq 4.6 \%)$, MVD ( $\left.\geq 7.0 / 0.95 \mathrm{~mm}^{2}\right)$ and VEGF expression (high) were significantly associated with a shorter period of DFS $(P=<0.0001,0.0199,0.0055$, $0.0027,0.0028$ and 0.0302 , respectively). In multivariate analysis, tumor grade and MVD were identified as independent worse prognostic factors for DFS in a stepwise multivariate logistic regression model $(P=0.0007,0.0152$, respectively, Table 6$)$. The presence of KIT exon 11 mutation was not correlated with DFS (data not shown).

\section{Discussion}

In the current study, in addition to the conventional prognostic factors such as tumor grade and Ki-67 LI, MVD was significantly associated with worse prognosis in GISTs. In addition, MVD was significantly associated with tumor size and tumor grade in GISTs. A similar relationship between MVD and prognosis has been reported in various kinds of carcinomas and sarcomas. ${ }^{26-28}$ The above-mentioned results provide an evidence that the evaluation of MVD may be useful for predicting aggressive behavior in GISTs.

We then found an overall close correlation between MVD and VEGF expressed by tumor cells in the present series of GISTs. Our result is 

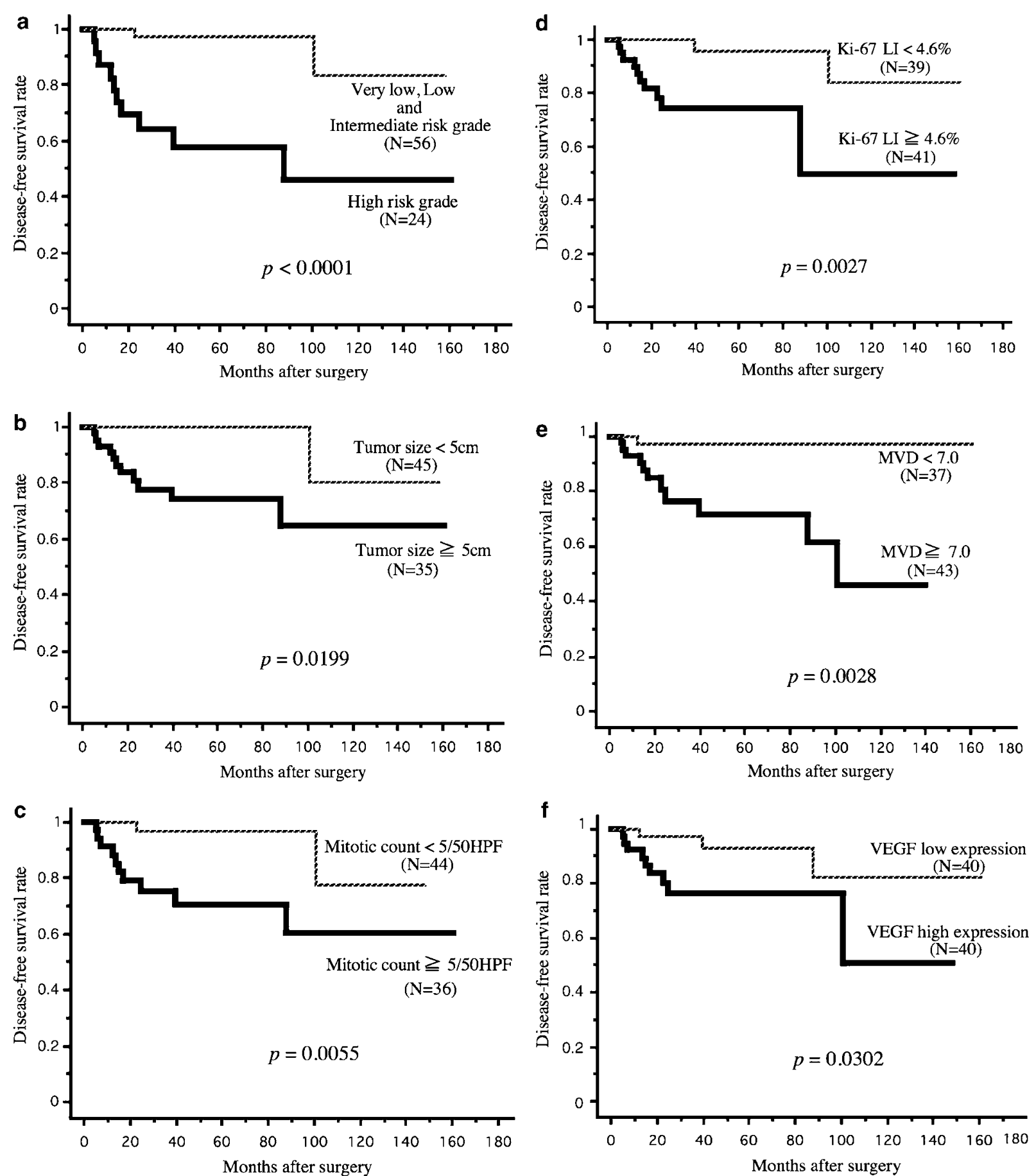

Figure 2 Kaplan-Meier analysis for 80 patients with GIST. (a) Twenty-four patients with high-grade GIST have significantly shorter DFS than 26 patients with very low + low-grade GIST and 30 patients with intermediate-grade GIST $(P<0.0001)$. (b) Thirty-five patients with large tumor size $(\geq 5 \mathrm{~cm})$ have significantly shorter DFS than 45 patients with small size $(<5 \mathrm{~cm})(P=0.0199)$. (c) Thirty-six patients with high-mitotic counts $(\geq 5 / 50 \mathrm{HPF})$ have significantly shorter DFS than 44 patients with low counts $(<5 / 50 \mathrm{HPF})(P=0.0055)$. (d) Forty-one patients with high Ki-67 LI $(\geq 4.6 \%)$ have a significantly shorter DFS than 39 patients with a low index $(<4.6 \%)$ $(P=0.0027)$. (e) Forty-three patients with many MVD ( $\geq 7.0)$ also have a significantly shorter DFS than 37 patients with little MVD $(<7.0)$ $(P=0.0028)$. (f) Forty patients with high VEGF expression also have a significantly shorter DFS than 40 patients with a low VEGF expression $(P=0.0302)$.

consistent with a previous report by Takahashi et al. $^{29}$ In general, angiogenesis is thought to be initiated by the paracrine release of angiogenic factors by tumor cells, such as VEGF, basic fibroblast growth factor and PDGF. ${ }^{30-32}$ Angiogenic factors induce endothelial cells to proliferate and migrate toward the tumor. VEGF is one of the well-studied angiogenic factors; it is produced and secreted by 
tumor cells and is associated with tumor neovascularization in various kind of malignant tumors. ${ }^{14,33,34}$ Likewise, VEGF expressed by GIST cells may function via a paracrine mechanism in angiogenesis in GIST.

As an unexpected result, VEGF expression and MVD were both higher in intestinal GISTs than in gastric GISTs. We still cannot show definite molecular basis for this finding. The finding, however, may explain in part why small intestinal GISTs have a tendency to be more aggressive than gastric tumors. ${ }^{35}$

In the current study, we have demonstrated the correlation among angiogenesis, VEGF expression and KIT genotype in GISTs. VEGF protein expression was higher in the non-KIT exon 11 mutant group than in the KIT exon 11 mutant group. Our results are consistent with a previous report by Antonescu et $a l^{16}$ that used a cDNA microarray study to show that the VEGF gene expression level was higher in KIT-wild GISTs than in KIT mutant GISTs. A recent study by Jin et $a l^{36}$ suggested that activated KIT signal regulated the expression of VEGF, based on the following data: (1) inhibition of KIT by imatinib resulted in the suppression of both $V E G F$ mRNA and VEGF protein in the GIST-T1 cells with KIT exon11 mutation; (2) stimulation of KIT signal by a treatment with stem cell factor, a ligand of KIT, upregulated the expression of VEGF in GIST cell line. However, we still cannot clarify the molecular mechanism, giving rise to the difference of VEGF expression depending on the KIT genotype. Although KIT is activated irrespective of KIT genotype in GISTs, ${ }^{3}$ gene expression profile is heterogeneous depending on KIT genotype; for example, BCL2, VEGF and MCSF were more highly expressed in KIT-wild GISTs than in KIT-mutant GISTs, and Mesothelin and CTNNB1 were more highly expressed in KIT exon 9 mutant than in KIT exon 11 mutant. ${ }^{16}$ The difference in KIT genotype might influence the status of activation of KIT downstream signaling and the transcription of target genes such as VEGF. Further study to elucidate the above hypothesis is needed.

Imatinib is a selective inhibitor of ABL (BCRABL), KIT and PDGFRA. Although imatinib is effective in GIST, its activity is heterogenous depending on the type of KIT mutation; tumors with KIT exon 11 mutation are more likely to respond to imatinib, and, in contrast, tumors with wild-type KIT or tumors with primary or secondary mutation in the kinase domain such as exon 13 and 17 are resistant to imatinib. ${ }^{17,18,37,38}$ SU11248 is a novel multitargeted tyrosine kinase inhibitor with antitumor and antiangiogenic activities by blocking KIT, PDGFRA and FLT3, as well as VEGFR. ${ }^{19}$ Interestingly, recent clinical studies have reported that sunitinib was effective in a subset of imatinibresistant GISTs. ${ }^{20-22}$ In the current study, non-KIT exon 11 mutant GISTs, which are probably less responsive to imatinib, showed higher expression of
VEGF than did KIT exon 11 mutant GISTs. These findings led us to speculate that sunitinib might be of advantage to imatinib-resistant (non-KIT exon 11 mutant) GISTs by inhibiting both KIT signaling in tumor cells and VEGF-VEGFR signaling in angiogenesis. Further molecular biological and clinical studies involving molecular therapeutic targets related to KIT genotype and angiogenesis are expected.

In this study, we detected KIT exon11 mutations in $64.3 \%$ of our series of GISTs and exon 9 mutations in $2.9 \%$. The reported frequency of exon 11 mutations in GISTs varies from 52 to $71 \% .^{3,4,6,39,40}$ A possible explanation for such variation may be related to the methodological difference in detecting mutations and to the difference in the types of tissue used for DNA extraction. ${ }^{5}$ In addition, the prevalence of the spindle-cell type of GISTs might influence the low frequency of PDGFRA gene mutation in the current study, because, in general, PDGFRA mutation is more frequently present in epithelioid-cell type GISTs than in spindle-cell type GISTs (most of our cases were spindle-cell type). ${ }^{41}$

In conclusion, we found that MVD was correlated with both VEGF overexpression and worse prognosis in GISTs. Our results suggest that angiogenesis measured as MVD is useful for predicting the aggressive biologic behavior of GIST, and that angiogenesis associated with VEGF may play an important role, at least in part, in the progression of GIST. In addition, the evaluation of MVD, VEGF expression and KIT genotype might provide novel insight into molecular-targeted therapy intended to inhibit angiogenesis and KIT signaling for each individual GIST.

\section{Acknowledgement}

We thank Naoko Kinukawa, PhD, Department of Medical Information Science, Kyushu University Hospital, for assistance with the statistical analysis. This study was supported in part by grants-in-Aid for Scientific Research from the Japan Society of the Promotion of Science, Grant Numbers 18590332 (Oda) and 18790248 (Yamamoto), Tokyo, Japan.

\section{References}

1 Miettinen M, Lasota J. Gastrointestinal stromal tumors-definition, clinical, histological, immunohistochemical, and molecular genetic features and differential diagnosis. Virchows Arch 2001;438:1-12.

2 Hirota S, Isozaki K, Moriyama Y, et al. Gain-of-function mutations of c-kit in human gastrointestinal stromal tumors. Science 1998;279:577-580.

3 Rubin BP, Singer S, Tsao C, et al. KIT activation is a ubiquitous feature of gastrointestinal stromal tumors. Cancer Res 2001;61:8118-8121.

4 Antonescu CR, Sommer G, Sarran L, et al. Association of KIT exon 9 mutations with nongastric primary site 
and aggressive behavior: KIT mutation analysis and clinical correlates of 120 gastrointestinal stromal tumors. Clin Cancer Res 2003;9:3329-3337.

5 Corless CL, Fletcher JA, Heinrich MC. Biology of gastrointestinal stromal tumors. J Clin Oncol 2004;22: 3813-3825.

6 Heinrich MC, Coreless CL, Duensing A, et al. PDGFRA activating mutations in gastrointestinal stromal tumors. Science 2003;299:708-710.

7 Hasegawa T, Matsuno Y, Shimoda T, et al. Gastrointestinal stromal tumor: consistent CD117 immunostaining for diagnosis, and prognostic classification based on tumor size and MIB-1 grade. Hum Pathol 2002;33:669-676.

8 Martin J, Poveda A, Llombart-Bosch A, et al. Deletions affecting codons 557-558 of the c-KIT gene indicate a poor prognosis in patients with completely resected gastrointestinal stromal tumors: a study by the Spanish Group for Sarcoma Research (GEIS). J Clin Oncol 2005;23:6190-6198.

9 Lasota J, Dansonka-Mieszkowska A, Stachura T, et al. Gastrointestinal stromal tumors with internal tandem duplications in $3^{\prime}$ end of KIT juxtamembrane domain occur predominantly in stomach and generally seem to have a favorable course. Mod Pathol 2003;16: 1257-1264.

10 Sabah M, Cummins R, Leader M, Kay E. Loss of heterozygosity of chromosome $9 p$ and loss of p16INK4A expression are associated with malignant gastrointestinal stromal tumors. Mod Pathol 2004;17:1364-1371.

11 Nakamura N, Yamamoto H, Yao T, et al. Prognostic significance of expressions of cell-cycle regulatory proteins in gastrointestinal stromal tumor and the relevance of the risk grade. Hum Pathol 2005;36: 828-837.

12 Hanahan D, Weinberg RA. The hallmarks of cancer. Cell 2000;100:57-70.

13 Weidner N, Semple JP, Welch WR, Folkman J. Tumor angiogenesis and metastasis: correlation in invasive breast carcinoma. N Engl J Med 1991;324:1-8.

14 Ferrara N. Davis-Smyth T: the biology of vascular endothelial growth factor (review). Endocr Rev 1997; 18:4-25.

15 Plate KH, Breier G, Weich HA, Risau W. Vascular endothelial growth factor is a potential tumour angiogenesis factor in human gliomas in vivo. Nature 1992; 359:845-848.

16 Antonescu CR, Viale A, Sarran L, et al. Gene expression in gastrointestinal stromal tumors is distinguished by KIT genotype and anatomic site. Clin Cancer Res 2004;10:3282-3290.

17 Debiec-Rychter M, Dumez H, Judson I, et al. Use of c-KIT/PDGFRA mutational analysis to predict the clinical response to imatinib in patients with advanced gastrointestinal stromal tumours entered on phase I and II studies of the EORTC Soft Tissue and Bone Sarcoma Group. Eur J Cancer 2004;40:689-695.

18 Heinrich MC, Corless CL, Demetri GD, et al. Kinase mutations and imatinib response in patients with metastatic gastrointestinal stromal tumor. J Clin Oncol 2003;21:4342-4349.

19 Mendel DB, Laird AD, Xin X, et al. In vivo antitumor activity of SU11248, a novel tyrosine kinase inhibitor targeting vascular endothelial growth factor and platelet-derived growth factor receptors: determination of a pharmacokinetic/pharmacodynamic relationship. Clin Cancer Res 2003;9:327-337.
20 Demetri GD, Desai J, Fletcher JA, et al. SU11248, a multi-targeted tyrosine kinase inhibitor, can overcome imatinib (IM) resistance caused by diverse genomic mechanisms in patients (pts) with metastatic gastrointestinal stromal tumor (GIST) (abstract). Proc Am Soc Clin Oncol 2004;22:3001.

21 Heinrich MC, Maki RG, Corless CL, et al. Sunitinib (SU) response in imatinib-resistant (IM-R) GIST correlates with KIT and PDGFRA mutation status (abstract). Proc Am Soc Clin Oncol 2006;24:9502.

22 Prenen H, Cools J, Mentens N, et al. Efficacy of the kinase inhibitor SU11248 against gastrointestinal stromal tumor mutants refractory to imatinib mesylate. Clin Cancer Res 2006;12:2622-2627.

23 Fletcher CD, Berman JJ, Corless C, et al. Diagnosis of gastrointestinal stromal tumors: a consensus approach. Hum Pathol 2002;33:459-465.

24 Horak ER, Leek R, Klenk N, et al. Angiogenesis, assessed by platelet/endothelial cell adhesion molecule antibodies, as indicator of node metastases and survival in breast cancer. Lancet 1992;340: 1120-1124.

25 Yamamoto $\mathrm{H}$, Oda Y, Kawaguchi K, et al. c-kit and PDGFRA mutations in extragastrointestinal stromal tumor (gastrointestinal stromal tumor of the soft tissue). Am J Surg Pathol 2004;28:279-288.

26 Weidner N, Carroll PR, Flax J, Blumenfeld W, Folkman J. Tumor angiogenesis correlates with metastasis in invasive prostate carcinoma. Am J Pathol 1993;143: 401-409.

27 Macchiarini P, Fontanini G, Hardin MJ, Squartini F, Angeletti CA. Relation of neovascularisation to metastasis of non-small-cell lung cancer. Lancet 1992;340: 145-146.

28 Kreuter M, Bieker R, Bielack SS, et al. Prognostic relevance of increased angiogenesis in osteosarcoma. Clin Cancer Res 2004;10:8531-8537.

29 Takahashi R, Tanaka S, Kitadai Y, et al. Expression of vascular endothelial growth factor and angiogenesis in gastrointestinal stromal tumor of the stomach. Oncology 2003;64:266-274.

30 Hanahan D, Folkman J. Patterns and emerging mechanisms of the angiogenic switch during tumorigenesis. Cell 1996;86:353-364.

31 Sato N, Beitz JG, Kato J, et al. Platelet-derived growth factor indirectly stimulates angiogenesis in vitro. Am J Pathol 1993;142:1119-1130.

32 Ninck S, Reisser C, Dyckhoff G, Helmke B, Bauer H, Herold-Mende C. Expression profiles of angiogenic growth factors in squamous cell carcinomas of the head and neck. Int J Cancer 2003;106: 34-44.

33 Choi WW, Lewis MM, Lawson D, et al. Angiogenic and lymphangiogenic microvessel density in breast carcinoma: correlation with clinicopathologic parameters and VEGF-family gene expression. Mod Pathol 2005;18:143-152.

34 Dalal S, Berry AM, Cullinane CJ, et al. Vascular endothelial growth factor: a therapeutic target for tumors of the Ewing's sarcoma family. Clin Cancer Res 2005;11:2364-2378.

35 Miettinen M, EI-Rifai W, HL Sobin L, Lasota J. Evaluation of malignancy and prognosis of gastrointestinal stromal tumors: a review. Hum Path 2002;33: 478-483.

36 Jin T, Nakatani H, Taguchi T, et al. STI571 (Glivec) suppresses the expression of vascular endothelial 
growth factor in the gastrointestinal stromal tumor cell line, GIST-T1. World J Gastroenterol 2006;12: 703-708.

37 Chen LL, Trent JC, Wu EF, et al. A missense mutation in KIT kinase domain 1 correlates with imatinib resistance in gastrointestinal stromal tumors. Cancer Res 2004;64:5913-5919.

38 Antonescu CR, Besmer P, Guo T, et al. Acquired resistance to imatinib in gastrointestinal stromal tumor occurs through secondary gene mutation. Clin Cancer Res 2005;11:4182-4190.
39 Taniguchi M, Nishida T, Hirota S, et al. Effect of c-kit mutation on prognosis of gastrointestinal stromal tumors. Cancer Res 1999;59:4297-4300.

40 Lasota J, Wozniak A, Sarlomo-Rikala M, et al. Mutations in exons 9 and 13 of KIT gene are rare events in gastrointestinal stromal tumors. A study of 200 cases. Am J Pathol 2000;157:1091-1095.

41 Wardelmann E, Neidt I, Bierhoff E, et al. c-kit mutations in gastrointestinal stromal tumors occur preferentially in the spindle rather than in the epithelioid cell variant. Mod Pathol 2002;15:125-136. 